\title{
Clinical Importance of Blood Drug Concentration of Oral Molecular Targeted Drugs for Renal Cell Carcinoma
}

\author{
Shinya Takasaki ${ }^{1}$, Yoshihide Kawasaki ${ }^{2}$, Masafumi Kikuchi ${ }^{1},{\text { Akihiro } \text { Ito }^{2} \text {, Hiroaki Yamaguchi }}^{1}$, and Nariyasu Mano ${ }^{1}$ \\ ${ }^{1}$ Department of Pharmaceutical Sciences and ${ }^{2}$ Department of Urology, Tohoku University Hospital, Aobaku, Sendai, \\ Miyagi, Japan
}

Corresponding author: Shinya Takasaki, Department of Pharmaceutical Sciences, Tohoku University Hospital, 1-1 Seiryo-machi, Aobaku, Sendai, Miyagi 980-8574, Japan; TEL: (+81)-022-717-7540; Fax: (+81)-022-717-7545; email: shinya takasaki@tohoku.ac.jp

Received, February 15, 2021; Revised, March 5, 2021; Accepted, March 10, 2021; Published, March 14, 2021

\begin{abstract}
Purpose: Therapeutic drug monitoring (TDM) is widely used in clinical practice to maximize drug efficacy and minimize toxicities. Currently, it is also practiced in the use of oral molecular targeted drugs. The objective of this study was to assess the clinical importance of measuring the systemic concentration of oral molecular targeted drugs used to treat renal cell carcinoma (RCC). Methods: The systemic concentrations of the oral molecular targeted drugs sorafenib, sunitinib, axitinib, pazopanib, and everolimus used for RCC were useful for therapeutic interventions, and clinical outcomes were evaluated retrospectively. Results: The interventional use of systemic drug concentration was confirmed in 26 of 87, and their categories are presented. The systemic concentration of sunitinib was useful in dose reduction and/or discontinuation $(\mathrm{n}=10)$, dose escalation $(n=3)$, and adherence monitoring $(n=2)$. Nine of the 10 patients whose dose was reduced showed reduced adverse event. Two patients who were intervened in adherence monitor showed improved adherence. For axitinib, dose reduction and/or discontinuation $(\mathrm{n}=1)$ and dose escalation $(\mathrm{n}=6)$ were confirmed. For pazopanib, dose reduction and/or discontinuation $(n=1)$ and drug interaction detection $(n=1)$ were confirmed, both of them were confirmed to have reduced adverse events. For everolimus, dose reduction and/or discontinuation $(\mathrm{n}=1)$ and drug interaction detection $(\mathrm{n}=1)$ were confirmed, a patient with reduced dose recovered from adverse events. Interventions for sorafenib were not identified. Conclusions: This study demonstrated that systemic concentrations of oral molecular targeted drugs for RCC were considered to be clinically useful for dose adjustment, monitoring of treatment adherence, and the detection of drug interactions. Moreover, this information could be successfully used to guide individualized therapy to maximize the antitumor effects of these drugs.
\end{abstract}

\section{INTRODUCTION}

Renal cell carcinoma (RCC), the most common type of kidney cancer, is widely treated with molecular targeted drugs and immune checkpoint inhibitors (1). Molecular targeted drugs include tyrosine kinase inhibitors (TKI) and mechanistic target of rapamycin inhibitors (mTORi), which show antitumor effects with different modes of action $(1,2)$. TKIs bind to tyrosine kinases and block the signals that facilitate RCC growth and proliferation, while mTORi block the transfer of phosphates and slow tumor growth (1, 2). In Japan, the TKIs sorafenib, sunitinib, axitinib, pazopanib, and cabozantinib, as well as the mTORi everolimus and temsirolimus are used for RCC treatment $(3,4)$. Although these targeted drugs show higher objective response rates and significantly prolong median progression-free survival more than other agents, they induce various adverse events such as diarrhea, fatigue, vomiting, myelosuppression, and interstitial pneumonia (5-11).

Therapeutic drug monitoring (TDM) is widely used in clinical practice for maximizing the efficacy and minimizing the toxicities of certain drugs. Recently, TDM has also been recommended and applied to anticancer drug therapy (12-14). TDM of methotrexate for leukemia and fluorouracil for colorectal cancer were reported to improve the clinical outcomes of cancer chemotherapy $(15,16)$. With oral targeted anticancer drugs, TDM of imatinib, a TKI used for chronic myeloid leukemia, has been recognized to be clinically beneficial for the optimal treatment management of the disease (1720). Pharmacokinetic/pharmacodynamic (PK/PD) studies of other anticancer drugs have been reported, and additional evidence accumulated in the future may be applicable to future applications of clinical TDM (12-14). 
Several PK/PD studies of the oral molecular targeted drugs sorafenib, sunitinib, axitinib, pazopanib, cabozantinib, and everolimus for use RCC therapy in Japan have been reported (14). Serum concentrations of sorafenib in Japanese patients and the area under the curve (AUC) of sorafenib and its metabolite sorafenib $\mathrm{N}$-oxide may predict severe adverse effects $(21,22)$. Sunitinib, which is metabolized by cytochrome P450 (CYP) $3 \mathrm{~A} 4$ to its active metabolite ( $N$-desethyl sunitinib), was evaluated as total sunitinib (sunitinib plus $N$ desethyl sunitinib) $(23,24)$. The level of sunitinib in the plasma was associated with positive clinical outcomes (23-29), and the target trough level is considered to be $50-100 \mathrm{ng} / \mathrm{mL}$ in patients with RCC (26-28).

The AUC of axitinib is associated with both efficacy and the presence of adverse events (30-32). From the PK/PD results of pazopanib, the target trough level is estimated to be 20.5 to $50.3 \mu \mathrm{g} / \mathrm{mL}$ $(33,34)$. The correlation between the plasma concentration of cabozantinib, the incidence of adverse events, and its antitumor effect is identified using population PK analysis (35). TDM of everolimus is commonly applied for the prevention of organ transplant rejection and treatment of tuberous sclerosis, but its benefit is not clear in cancer (36). An association between systemic levels of everolimus, its toxicity, and its antitumor effects is reported for cancer $(37,38)$. However, there is insufficient PK/PD data to support routine TDM of oral molecular targeted drugs in the treatment of RCC.

However, measuring the concentration of drugs in the plasma of patients has clinical benefits, including the avoidance of serious adverse events, assurance of efficacy, confirmation of treatment adherence, detection of drug interactions, and elucidation of the effects of other toxic substances when used concurrently (12-14). At our facility, systemic concentrations of sorafenib, sunitinib, axitinib, pazopanib, and everolimus (Table 1) have been measured in patients for their utility in personalized medicine using oral targeted therapies for the treatment of RCC. Hence, in this study, we report the clinical importance of measuring the systemic levels of sorafenib, sunitinib, axitinib, and everolimus in patients with RCC.

\section{METHODS}

\section{Patients}

The study included patients who received sorafenib, sunitinib, axitinib, pazopanib, and everolimus for the treatment of RCC at Tohoku University Hospital from November 2011 to January 2017. The patients were adults ( $\geq 20$ years old) with RCC who had an Eastern Cooperative Oncology Group (ECOG) performance status (PS) of $0,1,2$, or 3 . This study was performed according to the Declaration of Helsinki. The protocol was approved by the Ethics Committee of Tohoku University Graduate School of Medicine (No. 2010-481-1, 2011-385, 2011-634, 2012-1-444, 2014-1-150, 2015-1-866, and 2020-1806) and was carried out after obtaining written informed consent from all patients.

\section{Measurement of systemic drug concentration}

Systemic drug concentrations (in plasma and blood for TKIs and everolimus, respectively) of both inpatients and outpatients were analyzed using previously reported methods $(38-40)$.

\section{Evaluation of clinical utility}

The systemic drug concentrations were measured and reported to their attending physcian and pharmacist. Whenever the intervention was due to the systemic drug concentrations, the outcomes were retrospectively evaluated. The interventions were classified into the following four categories: (i) dose reduction and/or discontinuation, (ii) dose escalation, (iii) adherence monitoring, and (iv) drug interaction detection, all of which were defined as clinically useful (Table 2). In addition, clinical outcomes from interventions based on the plasma drug levels were evaluated retrospectively. PS was evaluated using the ECOG criteria. Adverse events were graded according to National Cancer Institute Common Terminology Criteria for Adverse events (NCI CTCAE), version 4.0.

\section{RESULTS}

A total 87 patients with RCC who were treated with targeted therapies were included in this study, and their baseline characteristics are shown in Table 3. The systemic concentrations of each drug showed a wide variation among the patients. Additionally, interventions based on measurements of systemic drug concentration were conducted in 26 patients, and those for each category and each clinical outcome are presented in Table 4. The plasma concentrations of sunitinib were used to intervene in the treatment by conducting dose reduction and/or discontinuation ( $(n=10)$, dose escalation $(n=3)$, and adherence monitoring $(n=2)$. Nine of the 10 patients 
who were intervened in dose reduction and/or discontinuation confirmed reduction of adverse event. Two patients who intervened in adherence monitor showed improved adherence.

For axitinib, dose reduction and/or discontinuation $(\mathrm{n}=1)$ and dose escalation $(\mathrm{n}=6)$ were confirmed. For pazopanib, dose reduction and/or discontinuation $(\mathrm{n}=1)$ and drug interaction detection $(n=1)$ were confirmed, both of them were confirmed to have reduced adverse events. For everolimus, dose reduction and/or discontinuation ( $\mathrm{n}$ $=1)$ and drug interaction detection $(\mathrm{n}=1)$ were confirmed, a patient with reduced dose recovered from adverse events. Interventions for sorafenib were not identified.

Table 1. Oral molecular targeted drugs for renal cell carcinoma (RCC) used in this study.

\begin{tabular}{|c|c|c|c|}
\hline Drug & Target molecule & Standard dosage & $\begin{array}{c}\text { Major adverse event based on previously } \\
\text { reported }\end{array}$ \\
\hline \multirow{5}{*}{ Sorafenib } & \multirow{5}{*}{ Tyrosine kinase } & \multirow{5}{*}{$400 \mathrm{mg}$ twice daily } & Diarrhea $(43 \%)$ \\
\hline & & & Rash or desquamation (40\%) \\
\hline & & & Fatigue $(37 \%)$ \\
\hline & & & Hand-foot skin reaction (30\%) \\
\hline & & & Alopecia $(27 \%)$ \\
\hline \multirow{5}{*}{ Sunitinib } & \multirow{5}{*}{ Tyrosine kinase } & \multirow{5}{*}{$\begin{array}{l}50 \mathrm{mg} \text { once daily } \\
4 \text { weeks on, } 2 \text { weeks off }\end{array}$} & Diarrhea (43\%) \\
\hline & & & Rash or desquamation ( $40 \%)$ \\
\hline & & & Fatigue (37\%) \\
\hline & & & Hand-foot skin reaction $(30 \%)$ \\
\hline & & & Alopecia (27\%) \\
\hline \multirow{5}{*}{ Axitinib } & \multirow{5}{*}{ Tyrosine kinase } & \multirow{5}{*}{$5 \mathrm{mg}$ twice daily } & Diarrhea $(55 \%)$ \\
\hline & & & Increased creatinine (55\%) \\
\hline & & & Hypertension (40\%) \\
\hline & & & Fatigue $(39 \%)$ \\
\hline & & & Hypocalcemia (39\%) \\
\hline \multirow{5}{*}{ Pazopanib } & \multirow{5}{*}{ Tyrosine kinase } & \multirow{5}{*}{$800 \mathrm{mg}$ once daily } & Aspartate aminotransferase increased (61\%) \\
\hline & & & Alanine aminotransferase increased (60\%) \\
\hline & & & Fatigue $(55 \%)$ \\
\hline & & & Leukopenia (43\%) \\
\hline & & & Thrombocytopenia (41\%) \\
\hline \multirow{5}{*}{ Everolimus } & \multirow{5}{*}{$\begin{array}{l}\text { Mechanistic target } \\
\text { of rapamycin }\end{array}$} & \multirow{5}{*}{$10 \mathrm{mg}$ once daily } & Anemia $(91 \%)$ \\
\hline & & & Hypercholesterolemia (76\%) \\
\hline & & & Hypertriglyceridemia (71\%) \\
\hline & & & Hyperglycemia (50\%) \\
\hline & & & Increased creatinine ( $46 \%)$ \\
\hline
\end{tabular}

Sorafenib (5), sunitinib (6), axitinib (9), pazopanib (10), and everolimus (8) were cited. 
Table 2. Categorization of interventions determined by measuring the systemic drug concentration of oral molecular targeted drugs.

\begin{tabular}{l|l}
\hline Category & \multicolumn{1}{c}{ Definition } \\
\hline $\begin{array}{l}\text { Dose reduction and/or } \\
\text { discontinuation } \\
\text { Dose escalation }\end{array}$ & $\begin{array}{l}\text { Systemic drug concentration was referenced for dose reduction and/or } \\
\text { discontinuation } \\
\text { Systemic drug concentration was referenced for dose escalation }\end{array}$ \\
Adherence monitoring & $\begin{array}{l}\text { Systemic drug concentration was referenced for adherence monitoring } \\
\text { Drug interaction detection }\end{array}$ \\
\hline
\end{tabular}

Table 3. Patient characteristics at the start of administering each oral molecular targeted drug.

\begin{tabular}{|c|c|c|c|c|c|}
\hline $\begin{array}{l}\text { Characteristic } \\
\text { Value and (range) }\end{array}$ & $\begin{array}{l}\text { Sorafenib, } \\
\qquad n=5\end{array}$ & $\begin{array}{c}\text { Sunitinib, } \\
\qquad \mathbf{n}=\mathbf{3 7}\end{array}$ & $\begin{array}{l}\text { Axitinib, } \\
\mathbf{n}=\mathbf{2 3}\end{array}$ & $\begin{array}{l}\text { Pazopanib, } \\
\qquad \mathbf{n}=\mathbf{1 0}\end{array}$ & $\begin{array}{l}\text { Everolimus, } \\
\qquad \mathbf{n}=12\end{array}$ \\
\hline Median age, yr & $67(57-73)$ & $64(30-83)$ & $64(31-83)$ & $71(60-81)$ & $64(32-78)$ \\
\hline Male/Female & $5 / 0$ & $26 / 11$ & $15 / 8$ & $7 / 3$ & $7 / 5$ \\
\hline Median weight, $\mathrm{kg}$ & $57.3(40.9-63.8)$ & $62.7(41.0-92.6)$ & $59.6(39.0-86.8)$ & $58.0(40.1-65.2)$ & $57.9(46.0-65.8)$ \\
\hline Median BMI, $\mathrm{kg} / \mathrm{m}^{2}$ & 20.1(17.4-23.6) & $23.4(18.4-33.7)$ & 22.7(17.7-29.8) & 21.0(18.4-27.7) & $21.7(16.3-26.2)$ \\
\hline Median AST, IU/L & $24(17-39)$ & $18(10-46)$ & $24(14-58)$ & $22(8-132)$ & $24(16-45)$ \\
\hline Median ALT, IU/L & $16(6-69)$ & $14(6-104)$ & $15(10-87)$ & $19(4-159)$ & $17(11-53)$ \\
\hline \multicolumn{6}{|l|}{ ECOG Performance Status, $\mathrm{n}$} \\
\hline 0 & 5 & 31 & 15 & 7 & 11 \\
\hline 1 & 0 & 5 & 5 & 0 & 1 \\
\hline 2 or more & 0 & 1 & 3 & 3 & 0 \\
\hline \multicolumn{6}{|l|}{ Previous regimens, $\mathrm{n}$} \\
\hline 0 & 0 & 31 & 0 & 4 & 0 \\
\hline 1 & 3 & 3 & 12 & 1 & 2 \\
\hline 2 & 2 & 2 & 4 & 0 & 8 \\
\hline 3 or more & 0 & 1 & 7 & 5 & 2 \\
\hline \multirow[t]{3}{*}{ Initial dose, mg (n) } & $800(n=4)$ & $50(\mathrm{n}=11)$ & $10(\mathrm{n}=18)$ & $600(\mathrm{n}=2)$ & $10(\mathrm{n}=10)$ \\
\hline & $600(\mathrm{n}=1)$ & $37.5(\mathrm{n}=17)$ & $6(n=5)$ & $400(n=8)$ & $7.5(\mathrm{n}=1)$ \\
\hline & & $25(\mathrm{n}=9)$ & & & $5(\mathrm{n}=1)$ \\
\hline systemic & 3,254 & $57.5^{\mathrm{a}}$ & 5.4 & 20,700 & 15.2 \\
\hline concentration, Median ng/mL & $(559-5,633)$ & $(22.4-196.5)^{\mathrm{a}}$ & $(0.2-22.0)$ & $(10,600-92,100)$ & $(2.8-28.0)$ \\
\hline
\end{tabular}

BMI, body mass index; AST, aspartate aminotransferase; ALT, alanine aminotransferase; ECOG, Eastern Cooperative

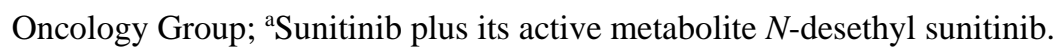


Table 4. Effect of interventions by the systemic drug concentration of oral molecular targeted drugs.

\begin{tabular}{lll}
\hline Drug & Intervention & Clinical outcome \\
\hline Sorafenib $(\mathrm{n}=5)$ & None & No change \\
\hline \multirow{2}{*}{ Sunitinib $(\mathrm{n}=37)$} & Dose reduction and/or discontinuation $(\mathrm{n}=10)$ & Reduced AE $(\mathrm{n}=9) ;$ No change $(\mathrm{n}=1)$ \\
& Dose escalation $(\mathrm{n}=3)$ & No change $(\mathrm{n}=3)$ \\
& Adherence monitoring $(\mathrm{n}=2)$ & Improved adherence $(\mathrm{n}=2)$ \\
\hline \multirow{2}{*}{ Axitinib $(\mathrm{n}=23)$} & Dose reduction and/or discontinuation $(\mathrm{n}=1)$ & No change $(\mathrm{n}=1)$ \\
& Dose escalation $(\mathrm{n}=6)$ & No change $(\mathrm{n}=6)$ \\
\hline \multirow{2}{*}{ Pazopanib $(\mathrm{n}=10)$} & Dose reduction and/or discontinuation $(\mathrm{n}=1)$ & Reduced AE $(\mathrm{n}=1)$ \\
& Drug interaction detection $(\mathrm{n}=1)$ & Reduced AE $(\mathrm{n}=1)$ \\
\hline \multirow{2}{*}{ Everolimus $(\mathrm{n}=12)$} & Dose reduction and/or discontinuation $(\mathrm{n}=1)$ & Reduced AV $(\mathrm{n}=1)$ \\
& Drug interaction detection $(\mathrm{n}=1)$ & No change $(\mathrm{n}=1)$ \\
\hline
\end{tabular}

AE: adverse event.

A case where the measurement of sunitinib concentration in the plasma was useful in predicting adverse events is shown in Figure 1. A 56-year-old female Japanese patient diagnosed with RCC initially underwent a partial left nephrectomy for clear cell carcinoma (cT2N0M0). Four years later, the patient presented with RCC with bone metastasis, and sunitinib therapy was initiated. The patient was prescribed $50 \mathrm{mg}$ sunitinib once daily for a regimen four weeks-on two weeks-off. Her PS, body weight, body mass index (BMI), aspartate aminotransferase (AST), alanine aminotransferase (ALT), and serum creatinine at the start of treatment were $3,72.8 \mathrm{~kg}$, $32.8 \mathrm{~kg} / \mathrm{m}^{2}, 16 \mathrm{IU} / \mathrm{L}, 11 \mathrm{IU} / \mathrm{L}$, and $0.8 \mathrm{mg} / \mathrm{dL}$, respectively. The patient was administered valsartan for hypertension, oxycodone for bone pain, esomeprazole for gastroesophageal reflux disease, and magnesium oxide for constipation. One week after starting sunitinib therapy, the patient experienced grade 1 hand-foot syndrome and grade 1 hypertension. On day 17 of the first course of treatment, sunitinib administration was interrupted because the patient presented with adverse events of grade 3 hypertension, grade 2 thrombocytopenia, and an abnormally high trough total sunitinib (sunitinib plus $N$-desethyl sunitinib) concentration of $196.9 \mathrm{ng} / \mathrm{mL}$, where the target trough range was 50 $100 \mathrm{ng} / \mathrm{mL}$ (26-28). Despite the withdrawal of sunitinib, the patient exhibited grade 3 thrombocytopenia on day 20 and grade 3 neutropenia on day 24. After recovering from the adverse events, the patient was started on a subsequent course of sunitinib $37.5 \mathrm{mg}$ for 2 weeks-on and 1 week-off. During the second course, the patient experienced grade 3 hypertension, grade 2 neutropenia, and grade 1 thrombocytopenia, and sunitinib trough levels were $120.7 \mathrm{ng} / \mathrm{mL}$ on day 15 . During the third course, grade 3 hypertension, grade 3 neutropenia, and grade 2 thrombocytopenia were observed. In the next course of treatment, sunitinib was started at a dose of $25 \mathrm{mg}$ and the treatment was continued for the following 2 years.

\section{DISCUSSION}

To our knowledge, this study was the first to report the measurement of drug systemic concentration of oral anticancer drugs as an intervention-determining parameter for Japanese patients with RCC. The interventions used in the categories defined in this study were: (1) dose reduction and/or discontinuation, (2) dose escalation, (3) adherence monitoring, and (4) drug interaction detection. The clinical outcomes from these interventions were also investigated and shown to reduce adverse events and improve adherence.

Although sunitinib was effective following dose reduction and treatment withdrawal, the frequency of severe adverse events of sunitinib such as thrombocytopenia, neutropenia, and anorexia was considered high in this study. With a target range of 50-100 ng/mL for plasma sunitinib level (26-28), this was used in 10 of 37 patients to determine the need for dose reduction and/or treatment discontinuation. In one case of a patient treated with sunitinib, as shown in Figure 1, it was inferred that serious adverse events such as bleeding due to thrombocytopenia could be avoided by measuring plasma sunitinib levels. The cause of the high plasma sunitinib concentration of this patient was unclear; however, genetic polymorphisms resulting to changes in the enzymes involved in sunitinib 
excretion and the clinical outcome may have affected her sunitinib levels $(41,42)$. In addition, the abnormally high sunitinib concentration of 196.9 $\mathrm{ng} / \mathrm{mL}$ observed on day 15 of the first treatment cycle might have been caused by the calcium channel blocker azelnidipine used for sunitinib-induced hypertension. The patient was treated with azelnidipine on days 7-15 for hypertension, after which it was changed to another calcium channel blocker, amlodipine. Calcium channel blockers including azelnidipine exhibit drug interaction with agents metabolized by CYP3A4 (43), and a case where the PK of sunitinib was affected by calcium channel blockers was reported (44). Takasaki et al. (45) reported that delayed excretion of sunitinib
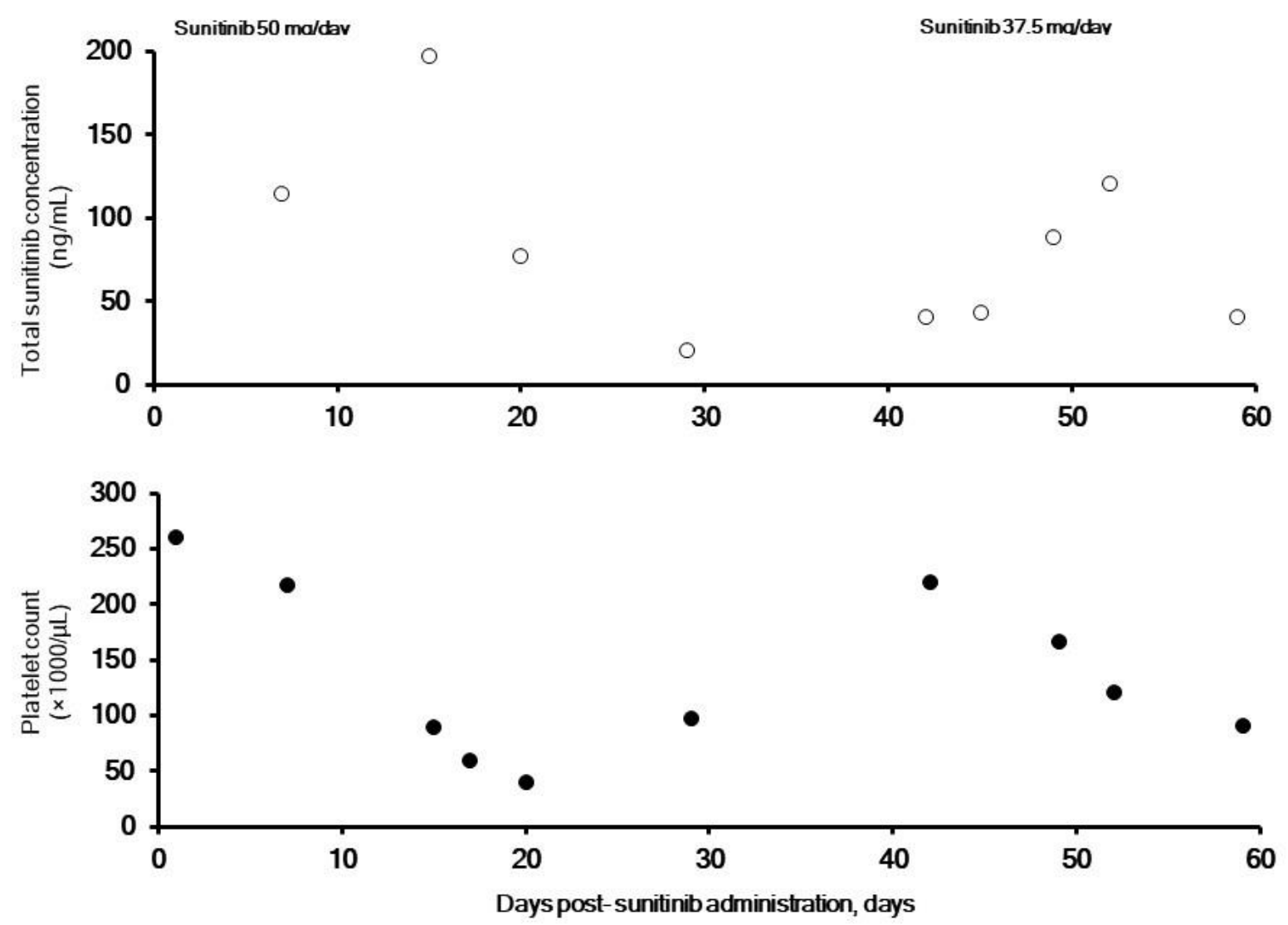

Figure 1. Plasma sunitinib concentrations (sunitinib plus $N$-desethyl sunitinib) and corresponding platelet counts in a patient with an abnormally high trough level of sunitinib and severe thrombocytopenia detected after starting sunitinib therapy.

caused serious adverse events. In addition, this study identified patients in whom no sunitinib was detected in their plasma, and who were later confirmed to have declined taking the drug because of the risk of adverse events. Thus, plasma sunitinib monitoring was useful for confirming abnormally high levels, drug interactions, and treatment adherence. These are important tools that could contribute to the avoidance of the serious adverse events related to sunitinib therapy and improve its therapeutic outcomes, as reported by Takasaki et al. (29).

Axitinib can be started at $5 \mathrm{mg}$ twice daily and can be increased if the patient has no issues with drug tolerability (9). In this study, plasma trough levels of axitinib were used as an indicator of the need for a dose increase in 6 of 23 patients compared to the PK data used in a previously reported study (46). PK/PD studies of axitinib have shown its AUC is an indicator of efficacy and toxicity. (30-32), and this AUC may be more beneficial than trough levels alone as an indicator of clinical outcome. However, because multiple-point systemic sampling is an obstacle to the routine calculation of AUC, its prediction using a limited sampling strategy is 
expected to be possible in future.

High plasma levels of pazopanib is associated with adverse events such as hypertension, and its beneficial effects was estimated to appears at $>20.5$ $\mu \mathrm{g} / \mathrm{mL}$ (33), based on which interventions were performed. In this study, 1 in 10 patients had their plasma levels used to determine the need for dose reduction. Compared with other drugs, there were fewer dose regulation interventions for pazopanib, which could be because its starting dose was lower than the usual $800 \mathrm{mg}$ and the incidence of adverse events was low. In addition, one case that was useful in discovering the drug interaction confirmed in this study has already been previously reported (47). Recently, Noda et al. (34) reported that the effective plasma concentration of pazopanib was in the range of 20.5 to $50.3 \mu \mathrm{g} / \mathrm{mL}$, and they recommended a dose adjustment to this target range in the future.

TDM of everolimus is common when it is used as an immunosuppressant and, recently, TDM of anticancer drugs was also reported to be useful (36). In this study, the blood concentration of everolimus was indexed at the target concentration of 5-15 $\mathrm{ng} / \mathrm{mL}$ as for the tumor tuberous sclerosis complex $(36,48)$. In this study, blood levels of everolimus were used to confirm the need for interventions regarding dose reduction and drug interactions in one patient each, respectively, and these cases have been previously reported $(49,38)$. In addition, the supporting evidence encourage the routine use of TDM in the future.

The TDM of sorafenib did not show any usefulness in this study, which may have been caused by the small number of cases $(\mathrm{n}=5)$. Shimada et al. (22) reported that in patients with hepatocellular carcinoma, the simultaneous TDM of sorafenib and sorafenib $N$-oxide may be important for the management of adverse events and improve the antitumor effects of the drug.

A limitation of this study was that the evidence was insufficient to support the performance of TDM with drugs other than sunitinib. Moreover, this study was not necessarily constrained to stay within target levels, and we investigated how retrospective analysis of systemic drug concentrations was used in the treatment of RCC. It would be useful to investigate clinical outcomes from patients randomize in both TDM and non-TDM groups.

\section{CONCLUSIONS}

This study demonstrated that sytemic concentrations of oral molecular targeted drugs for RCC were considered to be clinically useful for dose adjustment, monitoring of treatment adherence, and the detection of drug interactions. Moreover, this information could be successfully used to guide individualized therapy to maximize the antitumor effects of these drugs.

\section{ACKNOWLEDGEMENTS}

This work was supported by JSPS KAKENHI Grant Number $16 \mathrm{H} 00518$. We gratefully acknowledge all patients who allowed us to use their data in this manuscript and the medical staff who assisted us.

\section{CONFLICT OF INTEREST}

The authors no conflicts of interest to declare.

\section{REFERENCES}

1. Motzer RJ, Jonasch E, Agarwal N, et al. Kidney cancer, version 2.2017: Clinical practice guidelines in oncology. JNCCN J Natl Compr Cancer Netw, 2017; 15(6):804834. doi:10.6004/jncen.2017.0100.

2. Rini BI, Campbell SC, Escudier B. Renal cell carcinoma. Lancet, 2009; 373(9669):11191132. doi:10.1016/S0140-6736(09)60229-4.

3. Yoshimura K, Uemura H. Pharmacotherapies for renal cell carcinoma in Japan. Int J Urol, 2016; 23(3):194-202. doi:10.1111/iju.13008.

4. Tomita Y, Tatsugami K, Nakaigawa N, et al. Cabozantinib in advanced renal cell carcinoma: A phase II, open-label, singlearm study of Japanese patients. Int J Urol, 2020; 27(11):952-959. doi:10.1111/iju.14329.

5. Escudier B, Eisen T, Stadler WM, et al. Sorafenib in advanced clear-cell renal-cell carcinoma. N Engl J Med, 2007; 356(2):125134. doi:10.1056/NEJMoa060655.

6. Motzer RJ, Hutson TE, Tomczak P, et al. Sunitinib versus interferon alfa in metastatic renal-cell carcinoma. N Engl J Med, 2007; 356(2):115-124. doi:10.1056/NEJMoa065044.

7. Hudes G, Carducci M, Tomczak P, et al. Temsirolimus, interferon alfa, or both for advanced renal-cell carcinoma. J Urol, 2008; 179(2):497-498. doi:10.1016/j.juro.2007.10.039.

8. Motzer RJ, Escudier B, Oudard S, et al. Efficacy of everolimus in advanced renal cell 
carcinoma: a double-blind, randomised, placebo-controlled phase III trial. Lancet, 2008 ;372(9637):449-456. doi:10.1016/S0140-6736(08)61039-9.

9. Rini BI, Escudier B, Tomczak P, et al. Comparative effectiveness of axitinib versus sorafenib in advanced renal cell carcinoma (AXIS): A randomised phase 3 trial. Lancet, 2011; 378(9807):1931-1939. doi:10.1016/S0140-6736(11)61613-9.

10. Motzer RJ, Hutson TE, Cella D, et al. Pazopanib versus sunitinib in metastatic renal-cell carcinoma. N Engl J Med, 2013; 369(8):722-731.

doi:10.1056/nejmoa1303989.

11. Choueiri TK, Escudier B, Powles T, et al. Cabozantinib versus everolimus in advanced renal-cell carcinoma. N Engl J Med, 2015; 373(19):1814-1823.

doi:10.1056/nejmoa1510016.

12. Gao B, Yeap S, Clements A, Balakrishnar B, Wong M, Gurney H. Evidence for therapeutic drug monitoring of targeted anticancer therapies. J Clin Oncol, 2012; 30(32):40174025. doi:10.1200/JCO.2012.43.5362.

13. Widmer N, Bardin C, Chatelut E, et al. Review of therapeutic drug monitoring of anticancer drugs part two - targeted therapies. Eur J Cancer, 2014;50(12):2020-2036. doi:10.1016/j.ejca.2014.04.015.

14. Mueller-Schoell A, Groenland SL, ScherfClavel O, et al. Therapeutic drug monitoring of oral targeted antineoplastic drugs. Eur J Clin Pharmacol, Published online 2020. doi:10.1007/s00228-020-03014-8.

15. Evans WE, Relling MV, Rodman JH, Crom WR, Boyett JM, Pui CH. Conventional compared with individualized chemotherapy for childhood acute lymphoblastic leukemia. $\mathrm{N}$ Engl J Med, 1998; 338(8):499-505. doi:10.1056/NEJM199802193380803.

16. Gamelin E, Delva R, Jacob J, et al. Individual fluorouracil dose adjustment based on pharmacokinetic follow-up compared with conventional dosage: Results of a multicenter randomized trial of patients with metastatic colorectal cancer. J Clin Oncol, 2008; 26(13):2099-2105.

doi:10.1200/JCO.2007.13.3934.

17. Picard S, Titier K, Etienne G, et al. Trough imatinib plasma levels are associated with both cytogenetic and molecular responses to standard-dose imatinib in chronic myeloid leukemia. Blood, 2007; 109(8):3496-3499. doi:10.1182/blood-2006-07-036012.

18. Larson RA, Druker BJ, Guilhot F, et al. Imatinib pharmacokinetics and its correlation with response and safety in chronic-phase chronic myeloid leukemia: A subanalysis of the IRIS study. Blood, 2008; 111(8):40224028. doi:10.1182/blood-2007-10-116475.

19. Takahashi N, Wakita H, Miura M, et al. Correlation between imatinib pharmacokinetics and clinical response in Japanese patients with chronic-phase chronic myeloid leukemia. Clin Pharmacol Ther, 2010; 88(6):809-813. doi:10.1038/clpt.2010.186.

20. Miura M. Therapeutic drug monitoring of imatinib. Ann Oncol, 2015; 26(5):vii38. doi:10.1093/annonc/mdv432.01.

21. Fukudo M, Ito T, Mizuno T, et al. Exposuretoxicity relationship of sorafenib in Japanese patients with renal cell carcinoma and hepatocellular carcinoma. Clin Pharmacokinet, 2014; 53(2):185-196. doi:10.1007/s40262-013-0108-z.

22. Shimada M, Okawa H, Kondo Y, et al. Monitoring serum levels of sorafenib and its $\mathrm{N}$-oxide is essential for long-term sorafenib treatment of patients with hepatocellular carcinoma. Tohoku J Exp Med, 2015; 237(3):173-182. doi:10.1620/tjem.237.173.

23. Adams VR, Leggas M. Sunitinib malate for the treatment of metastatic renal cell carcinoma and gastrointestinal stromal tumors. Clin Ther, 2007; 29(7):1338-1353. doi:10.1016/j.clinthera.2007.07.022.

24. Goodman VL, Rock EP, Dagher R, et al. Approval summary: sunitinib for the treatment of imatinib refractory or intolerant gastrointestinal stromal tumors and advanced renal cell carcinoma. Clin Cancer Res, 2007; 13(5):1367-1373. doi:10.1158/10780432.CCR-06-2328.

25. Houk BE, Bello CL, Poland B, Rosen LS, Demetri GD, Motzer RJ. Relationship between exposure to sunitinib and efficacy and tolerability endpoints in patients with cancer: results of a pharmacokinetic/pharmacodynamic metaanalysis. Cancer Chemother Pharmacol, 2010; 66(2):357-371. doi:10.1007/s00280009-1170-y.

26. Mendel DB, Douglas Laird A, Xin X, et al. In vivo antitumor activity of SU11248, a novel 
tyrosine kinase inhibitor targeting vascular endothelial growth factor and plateletderived growth factor receptors: Determination of a pharmacokinetic/ pharmacodynamic relationship. Clin Cancer Res, 2003; 9(1 I):327-337.

27. Faivre S, Delbaldo C, Vera K, et al. Safety, pharmacokinetic, and antitumor activity of SU11248, a novel oral multitarget tyrosine kinase inhibitor, in patients with cancer. J Clin Oncol, 2006; 24(1):25-35. doi:10.1200/JCO.2005.02.2194.

28. Noda S, Otsuji T, Baba M, et al. Assessment of sunitinib-induced toxicities and clinical Outcomes Based on Therapeutic Drug Monitoring of Sunitinib for Patients with Renal Cell carcinoma. Clin Genitourin Cancer, 2015; 13(4):350-358. doi:10.1016/j.clgc.2015.01.007.

29. Takasaki S, Kawasaki Y, Kikuchi M, et al. Relationships between sunitinib plasma concentration and clinical outcomes in Japanese patients with metastatic renal cell carcinoma. Int J Clin Oncol, 2018; 23(5):936943. doi:10.1007/s10147-018-1302-7.

30. Rini BI, Garrett M, Poland B, et al. Axitinib in metastatic renal cell carcinoma: results of a pharmacokinetic and pharmacodynamic analysis. J Clin Pharmacol, 2013;53(5):491504. doi:10.1002/jcph.73.

31. Kato H, Sassa N, Miyazaki M, et al. Association of axitinib plasma exposure and genetic polymorphisms of $\mathrm{ABC}$ transporters with axitinib-induced toxicities in patients with renal cell carcinoma. Cancer Chemother Pharmacol, 2016; 78(4):855-862. doi:10.1007/s00280-016-3145-0.

32. Miura $\mathrm{Y}$, Imamura CK, Uchino $\mathrm{K}$, et al. Individualized dosing of axitinib based on first-dose area under the concentration-time curve for metastatic renal-cell carcinoma. Clin Genitourin Cancer, 2019; 17(1):e1-e11. doi:10.1016/j.clgc.2018.09.015.

33. Suttle AB, Ball HA, Molimard M, et al. Relationships between pazopanib exposure and clinical safety and efficacy in patients with advanced renal cell carcinoma. $\mathrm{Br} \mathrm{J}$ Cancer, 2014; 111(10):1909-1916. doi:10.1038/bjc.2014.503.

34. Noda S, Yoshida T, Hira D, et al. Exploratory investigation of target pazopanib concentration range for patients with renal cell carcinoma. Clin Genitourin Cancer,
2019; 17(2):e306-e313.

doi:10.1016/j.clgc.2018.12.001.

35. Lacy S, Nielsen J, Yang B, Miles D, Nguyen L, Hutmacher M. Population exposureresponse analysis of cabozantinib efficacy and safety endpoints in patients with renal cell carcinoma. Cancer Chemother Pharmacol, 2018;81(6):1061-1070. doi:10.1007/s00280-018-3579-7.

36. Shipkova M, Hesselink DA, Holt DW, et al. Therapeutic drug monitoring of everolimus: a consensus report. Ther Drug Monit, 2016; 38(2):143-169. doi:10.1097/FTD.0000000000000260.

37. Ravaud A, Urva SR, Grosch K, Cheung WK, Anak O, Sellami DB. Relationship between everolimus exposure and safety and efficacy: meta-analysis of clinical trials in oncology. Eur J Cancer, 2014; 50(3):486-495. doi:10.1016/j.ejca.2013.11.022.

38. Takasaki S, Yamaguchi H, Kawasaki Y, et al. Long-term relationship between everolimus blood concentration and clinical outcomes in Japanese patients with metastatic renal cell carcinoma: a prospective study. J Pharm Heal Care Sci, 2019; 5(1):1-9. doi:10.1186/s40780-019-0135-5.

39. Shimada M, Okawa H, Maejima T, et al. A Quantitative HPLC-UV method for determination of serum sorafenib and sorafenib $\mathrm{N}$-oxide and its application in hepatocarcinoma patients. Tohoku J Exp Med, 2014; 233(2):103-112. doi:10.1620/tjem.233.103.

40. Takasaki S, Tanaka M, Kikuchi M, et al. Simultaneous analysis of oral anticancer drugs for renal cell carcinoma in human plasma using liquid chromatography/electrospray ionization tandem mass spectrometry. Biomed Chromatogr, 2018; 32(6):1-8. doi:10.1002/bmc.4184.

41. Diekstra MHM, Swen JJ, Boven E, et al. CYP3A5 and ABCB1 polymorphisms as predictors for sunitinib outcome in metastatic renal cell carcinoma. Eur Urol, 2015; 68(4):621-629.

doi:10.1016/j.eururo.2015.04.018.

42. Garcia-Donas J, Esteban E, Leandro-García LJ, et al. Single nucleotide polymorphism associations with response and toxic effects in patients with advanced renal-cell carcinoma treated with first-line sunitinib: a 
multicentre, observational, prospective study. Lancet Oncol, 2011; 12(12):1143-1150. doi:10.1016/S1470-2045(11)70266-2.

43. Zhou YT, Yu LS, Zeng S, Huang YW, Xu HM, Zhou Q. Pharmacokinetic drug-drug interactions between 1,4-dihydropyridine calcium channel blockers and statins: Factors determining interaction strength and relevant clinical risk management. Ther Clin Risk Manag, 2014; 10(1):17-26. doi:10.2147/TCRM.S55512.

44. Da Silva F, Thomas-Schoemann A, Huillard $\mathrm{O}$, Goldwasser F, Blanchet B. Benefit of therapeutic drug monitoring to disclose pharmacokinetic interaction between sunitinib and calcium channel blocker. Ann Oncol, 2016; 27(8):1651-1652. doi:10.1093/annonc/mdw182.

45. Takasaki S, Kikuchi M, Kawasaki Y, et al. Severe toxicity induced by accumulation of active sunitinib metabolite in a Japanese patient with renal cell carcinoma: a case report. J Med Case Rep, 2017; 11(1):1-4. doi:10.1186/s13256-016-1185-z.

46. Pithavala YK, Tortorici M, Toh M, et al.
Effect of rifampin on the pharmacokinetics of axitinib (AG-013736) in Japanese and Caucasian healthy volunteers. Cancer Chemother Pharmacol, 2010; 65(3):563-570. doi:10.1007/s00280-009-1065-y.

47. Takasaki S, Adachi H, Kawasaki Y, et al. Importance of therapeutic drug monitoring to detect drug interaction between pazopanib and warfarin: a case report. J Pharm Pharm Sci, 2020; 23(1):200-205. doi:10.18433/jpps30868.

48. Franz DN, Belousova E, Sparagana S, et al. Efficacy and safety of everolimus for subependymal giant cell astrocytomas associated with tuberous sclerosis complex (EXIST-1): a multicentre, randomised, placebo-controlled phase 3 trial. Lancet (London, England), 2013; 381(9861):125132. doi:10.1016/S0140-6736(12)61134-9.

49. Takasaki S, Kikuchi M, Kawasaki Y, et al. A case of renal cell carcinoma with high everolimus blood concentrations and hyperglycemia due to everolimus-induced hepatic dysfunction. Gan To Kagaku Ryoho, 2017; 44(1):87-89. 